\title{
Foreword to special issue on Design, Test, Integration and Packaging of MEMS/MOEMS, 2008
}

\author{
Bernard Courtois $\cdot$ Bernd Michel
}

Published online: 26 May 2009

(C) Springer-Verlag 2009

The symposium on Design, Test, Integration and Packaging of MEMS/MOEMS (DTIP) was held in Nice, France, 9-11 April 2008, as a follow up to previous issues held in 1999 and 2000 in Paris, France, in 2001, 2002, 2003 in Mandelieu-La Napoule, France, in 2004 and 2005 in Montreux, Switzerland, and in 2006 and 2007 in Stresa, Italy. This series of symposia is a unique single-meeting event expressly planned to bring together participants interested in manufacturing microstructures and participants interested in design tools to facilitate the conception of these microstructures. The symposium is traditionally composed of two conferences running in parallel: one on CAD, Design and Test (CDT), and another one on Microfabrication, Integration and Packaging (MIP). In addition, participants of both conferences can attend invited talks and workshops/special sessions.

This special issue is collecting reviewed and unabridged versions of papers presented at the symposium. The papers have been again refereed, along the usual refereeing process in force at Microsystem Technologies. We are proud to offer these papers to the readers of this journal now.

From 36 revised papers submitted to this special issue, 26 papers have been finally selected. They cover a broad range of topics. They appear in the special issue in the following order. We initially start with two papers on design and modeling. Next we have three papers on BioMEMS, followed by eight papers on devices and components. We finally have thirteen papers dealing with manufacturing, characterization, assembly and integrated processes.

We hope that you enjoy these contributions as much as we did.

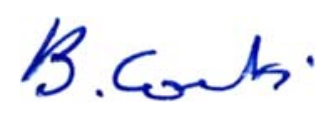

Bernard Courtois

DTIP Chair and Guest Editor, MST

$$
\text { B. Mild }
$$

Bernd Michel

Editor-in-Chief, MST

B. Courtois $(\square)$

CMP, 46 Avenue Felix Viallet,

38031 Grenoble Cedex, France

e-mail: Bernard.courtois@imag.fr

B. Michel

Fraunhofer Institute for Reliability and Microintegration (IZM)

Berlin, Gustav-Meyer-Allee 25, 13355 Berlin, Germany

e-mail: Bernd.michel@izm.fraunhofer.de 